\title{
6-BENZILAMINOPURINA E ÁCIDO INDOLBUTÍRICO NA MULTIPLICAÇÃO IN VITRO DA AMOREIRA - PRETA (Rubus idaeus L.), cv. TUPY
}

\author{
6-BENZYLAMINO PURINE AND INDOL BUTYRIC ACID ON THE IN VITRO \\ MULTIPLICATION OF BLACKBERRY (Rubus idaeus), cv. TUPY
}

\author{
Alan Cristiano Erig ${ }^{1}$ Andrea De Rossi ${ }^{1}$ Gerson Renan de Luces Fortes ${ }^{2}$
}

RESUMO

\begin{abstract}
$O$ presente trabalho avaliou o efeito de diferentes

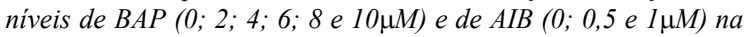
multiplicação in vitro da amoreira-preta cv. Tupy. O meio utilizado foi o MS suplementado com 100mg. $\ell^{l}$ de mio-inositol, 30g. $\ell^{1}$ de sacarose e 6g. $\ell^{1}$ de ágar. Após a inoculação, as culturas foram mantidas em sala de cultura com 16 horas de fotoperiodo, temperatura de $25 \pm 2^{\circ} \mathrm{C}$ e radiação de $25 \mu$ moles. $m^{-2} \cdot s^{-1}$. $O$ número de gemas e o número de brotações foram avaliados com intervalo semanal, num total de quatro avaliações, e, na última avaliação, considerou-se a altura da brotação, bem como foi determinada a taxa de multiplicação. $O$ maior número de gemas foi obtido com $2 \mu M$ de BAP e, na ausência de AIB, enquanto o maior número de brotações foi atingido, até a terceira semana de cultivo, com 2 e $4 \mu M$ de BAP. Para altura das brotações, tanto na ausência como no nivel de $1 \mu M$ de $A I B$, o aumento nas concentrações de BAP resultou na diminuição do comprimento das brotações linearmente. Observou-se, de modo geral, com o aumento dos niveis de BAP, para todas as doses de $A I B$, uma redução na altura das brotações. A concentração de $1 \mu M$ de AIB associado com BAP influenciou negativamente a

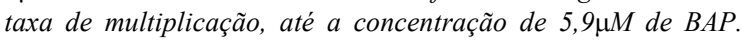
Quando utilizado isoladamente, o BAP promoveu aumento na

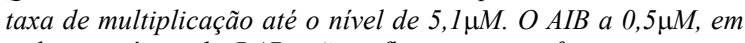
todos os niveis de BAP, não influenciou significativamente na taxa de multiplicação.
\end{abstract}

Palavras-chave: reguladores de crescimento; micropropagação; cultura de tecidos.

\section{SUMMARY}

This work aimed to evaluate the effect of different $B A P$ levels $(0 ; 2 ; 4 ; 6 ; 8$ and $10 \mu M)$ and IBA $(0 ; 0.5$ and $1 \mu M)$ on the in vitro multiplication of blackberry, cv. Tupy. The MS nutrient medium was supplemented with myo-inositol (100mg. $\left.\ell^{-1}\right)$, sucrose $\left(30 \mathrm{~g} \cdot \ell^{-1}\right)$ and agar $\left(6 \mathrm{~g} \cdot \ell^{-1}\right)$. The cultures were inoculated and then kept at a 16 hour-photoperiod, temperature of $25 \pm 2^{\circ} \mathrm{C}$ and 25 umoles. $m^{-2} \cdot s^{-1}$ radiation. The number of buds and shoots was evaluated weekly for one month. In the final evaluation, it was also taken into consideration the plantlet height and the rate of multiplication. In the absence of IBA, it was observed a higher number of buds, whereas the presence of BAP in the medium, promoted the highest number of buds at $2 \mu M$, which was achieved in the third week of cultivation. IBA at 0 and $1 \mu M$ promoted a linear decrease in plantlet height when associated with increase in BAP concentrations. It was also observed that an increase in BAP levels for all IBA levels reduced the plantlet height. IBA at $1 \mu M$ associated with BAP influenced negatively the rate of multiplication at 5.9 $\mu M$ BAP. BAP with no IBA addition promoted an increase in the rate of multiplication up to $5.1 \mu \mathrm{M}$. $I B A$ at $0.5 \mu M$, associated with all levels of $B A P$, did not influence significantly the rate of multiplication.

Key words: growth regulators; micropropagation; tissue culture.

\section{INTRODUÇÃO}

No RS, a amoreira-preta já é uma alternativa de renda aos pequenos e médios produtores, sendo que, na zona sul do estado são cultivados 40 hectares, enquanto, na Depressão Central e no Vale do Caí são cultivados 50 e 65 hectares da fruta, respectivamente (RODRIGUES, 1999).

\footnotetext{
${ }^{1}$ Alunos do Programa de Pós-graduação em Agronomia, área de concentração Fruticultura de Clima Temperado, Faculdade de Agronomia Eliseu Maciel, Universidade Federal de Pelotas, CP. 354, 96001-970, Pelotas, RS. E-mail: acerig@ufpel.tche.br. Autores para correspondência.

${ }^{2}$ Engenheiro Agrônomo, Doutor, Pesquisador da EMBRAPA Clima Temperado, CP. 403, Pelotas, RS. E-mail: gerson@cpactembrapa.br.
} 
A propagação da amoreira - preta, que pertence à família Rosaceae, gênero Rubus, dá-se principalmente por meio de estacas de raiz e mesmo de hastes novas (BASSOLS \& MOORE, 1979; BASSOLS, 1980).

É crescente o interesse pelo uso da micropropagação como um método alternativo de propagação vegetativa de árvores frutíferas. No entanto, existe a necessidade de se ajustar, para cada espécie, e/ou cultivar, as melhores condições de cultivo, para que se obtenha sucesso no processo (ZIMMERMAN, 1981). No caso da amoreira-preta, os explantes mais indicados na multiplicação clonal in vitro são ápices caulinares, gemas axilares e meristemas que normalmente mantêm a fidelidade genotípica da planta matriz (GRATTAPAGLIA \& MACHADO, 1990).

Um dos objetivos da micropropagação é a maximização da multiplicação de gemas. Muita atenção para sua obtenção tem sido dada com a manipulação de substâncias de crescimento no meio de cultura (BHOJWANI et al., 1984; LEE \& KO, 1984; MARINO, 1984). O crescimento e a morfogênese in vitro são fatores regulados pela interação e balanço dos reguladores de crescimento existentes no meio de cultura, principalmente auxinas e citocininas (GEORGE \& SHERRINGTON, 1984).

As citocininas são utilizadas para quebrar a dominância apical dos brotos, e aumentar a taxa de multiplicação. Deste modo, ocorre um grande número de brotações por meio do crescimento de meristemas laterais (SRISKANDARAJAH et al., 1982; HU \& WANG, 1983).

As auxinas, apesar de não promoverem a proliferação de brotações axilares, podem incrementar o crescimento da cultura (HU \& WANG, 1983). Uma das possíveis ações da auxina no meio de multiplicação seria a anulação do efeito supressivo das altas concentrações de citocinina sobre a elongação das brotações axilares, restaurando o crescimento normal das mesmas (LUNDERGAN \& JANICK, 1980).

Dentre os reguladores de crescimento comumente usadas no cultivo in vitro da amoreirapreta estão a 6-benzilaminopurina (BAP) e o ácido indol butírico (AIB) (DONNELLY et al., 1980). BROOME \& ZIMMERMAN (1978), por exemplo, obtiveram uma rápida proliferação de brotos, a partir de gemas axilares das cultivares Smothstem e US 64-39-2, com o emprego de BAP $\left(1,0 \mathrm{mg} \cdot \ell^{-1}\right)+\mathrm{AG}_{3}$ $\left(0,1 \mathrm{mg} \cdot \ell^{-1}\right)+\operatorname{AIB}\left(1,0 \mathrm{mg} \cdot \ell^{-1}\right)$.
O trabalho objetivou estudar o efeito de concentrações de benzilaminopurina (BAP) e ácido indol butírico (AIB) na multiplicação in vitro da amoreira - preta cv. Tupy.

\section{MATERIAL E MÉTODOS}

O experimento foi conduzido no Laboratório de Cultura de Tecidos da Embrapa Clima Temperado, em Pelotas - RS, onde segmentos caulinares de amoreira - preta (Rubus idaeus L.), cultivar Tupy, com duas gemas, provenientes de ápices de plantas mantidas in vitro, foram utilizados como explantes.

O meio de cultura utilizado foram os sais e vitaminas do MS (MURASHIGE \& SKOOG, 1962), adicionado de $100 \mathrm{mg} \cdot \ell^{-1}$ de mio-inositol, $30 \mathrm{~g} \cdot \ell^{-1}$ de sacarose e $6 \mathrm{~g} \cdot \ell^{-1}$ de ágar. $\mathrm{O} \mathrm{pH}$ do meio de cultura foi ajustado para 5,9 antes da inclusão do ágar e, posteriormente, autoclavado a $121^{\circ} \mathrm{C}$ e $1,5 \mathrm{~atm}$ por 15 minutos.

Foram usados frascos com capacidade de $250 \mathrm{~m} \ell$, cada um com $30 \mathrm{~m} \ell$ de meio de cultura. Os tratamentos foram BAP em seis níveis $(0 ; 2 ; 4 ; 6 ; 8$ e $10 \mu \mathrm{M})$ combinados com AIB em três níveis $(0 ; 0,5 \mathrm{e}$ $1 \mu \mathrm{M})$. O delineamento experimental foi o de blocos ao acaso, com quatro repetições por tratamento, totalizando-se 72 parcelas; cada repetição consistiu de um frasco com cinco explantes.

Após a inoculação, os frascos com explantes foram mantidos em sala de crescimento com 16 horas de fotoperíodo, temperatura de $25 \pm$ $2^{\circ} \mathrm{C}$ e radiação de $25 \mu$ moles. $\mathrm{m}^{-2} \cdot \mathrm{s}^{-1}$. Foram realizadas quatro avaliações com intervalos semanais, sendo observados os números de gemas e de brotações, e na última avaliação, computou-se a altura da brotação, e foi determinada a taxa de multiplicação. A análise dos dados foi realizada por regressão polinomial, através do uso do software SANEST (ZONTA \& MACHADO, 1987).

\section{RESULTADOS E DISCUSSÃO}

Observou-se um comportamento quadrático, para todos os níveis de BAP e AIB, no que diz respeito ao número de gemas (Figuras 1 e 2). Os maiores números de gemas foram obtidos com a concentração de $2 \mu \mathrm{M}$ de $\operatorname{BAP}(6,26)$ e na ausência de AIB $(6,16)$, sendo este resultado evidenciado mais pronunciadamente a partir da segunda semana de cultivo. SKIRVIN et al. (1981) e NEZI $\boldsymbol{e}$ t al. (1998), trabalhando na multiplicação in vitro com 


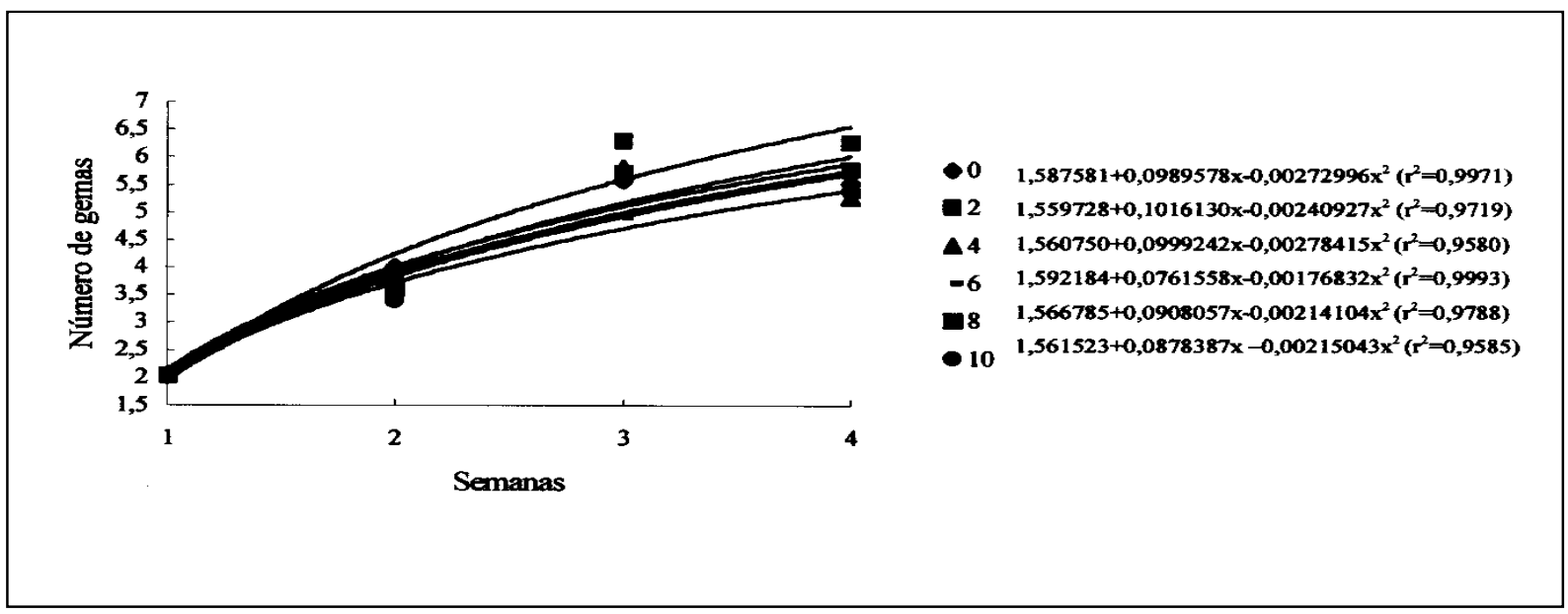

Figura 1 - Número de gemas de amoreira-preta cv. Tupy sob diferentes concentrações de BAP ( $\mu$ M), no período de 4 semanas. Pelotas, 2000.

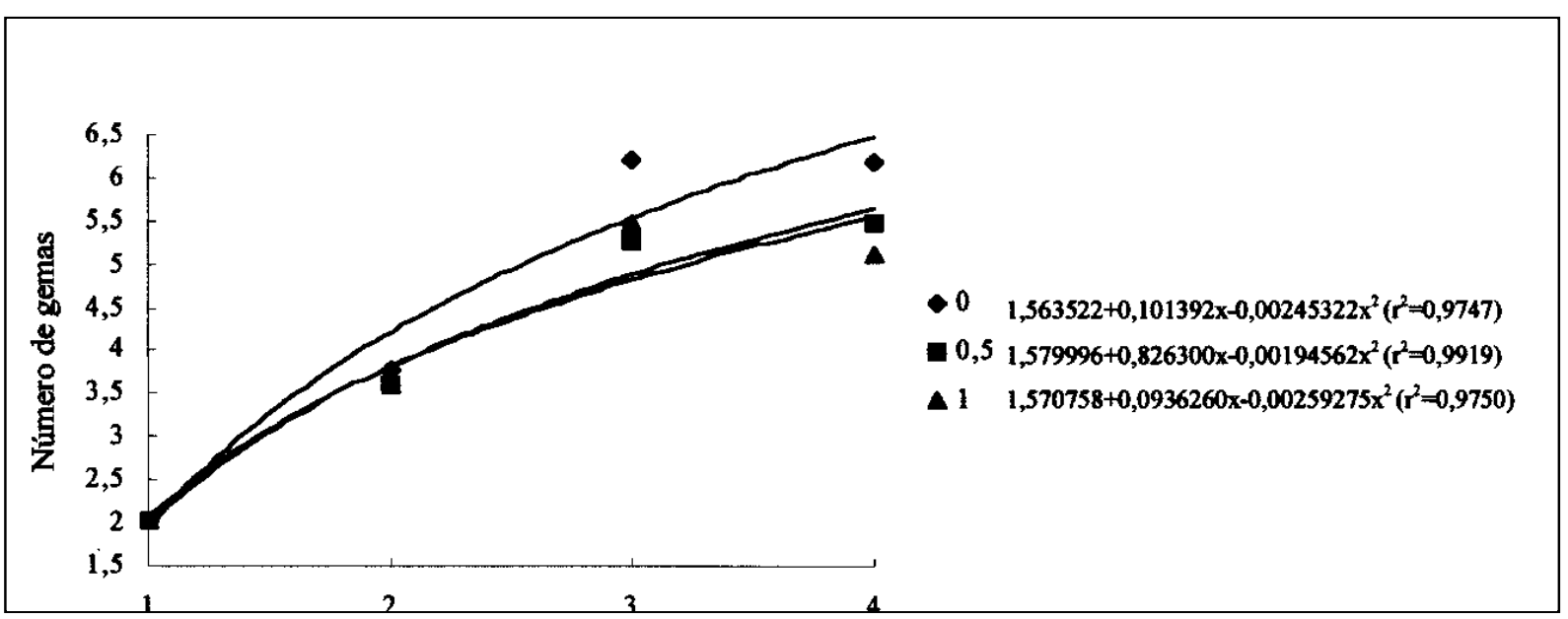

Figura 2 - Número de gemas de amoreira-preta cv. Tupy sob diferentes concentrações de AIB ( $\mu \mathrm{M})$, no período de 4 semanas. Pelotas, 2000.

cultivares Thornless Boysenberry e Thornless Youngberry em um primeiro trabalho e a cultivar Guarani num segundo estudo, obtiveram maior número de gemas em meio MS com o uso de BAP nas concentrações de 8,8 e $5 \mu \mathrm{M}$, respectivamente, diferindo dos resultados obtidos neste trabalho, no qual, conforme já salientado, o melhor nível de BAP foi de $2 \mu \mathrm{M}$. Esta diferença provavelmente se deve ao emprego de diferentes genótipos.

Com relação ao BAP (Figura 3), até a terceira semana de multiplicação, as concentrações de 2 e $4 \mu \mathrm{M}$ foram responsáveis pelo maior número de brotações $(0,67$ e 0,87 , respectivamente), sendo que o nível de $2 \mu \mathrm{M}$ é representado por curva linear crescente e o $4 \mu \mathrm{M}$, por uma curva quadrática. $\mathrm{Na}$ última avaliação (quarta semana), os níveis de 2, 4 e $6 \mu \mathrm{M}$ de BAP apresentaram resultados semelhantes.
MAYER et al. (1996), trabalhando com a cultivar Cherokee, obtiveram melhor proliferação de brotos em meio contendo $4,4 \mu \mathrm{M}$ BAP. Para GEORGE (1996), a associação, no meio de cultura, de $0,04 \mu \mathrm{M}$ até $17 \mu \mathrm{M}$ de BAP (dependendo da cultivar) mais $0,5 \mu \mathrm{M}$ de AIB induzem a proliferação de partes aéreas. A variável número de brotações, na ausência de AIB mostrou comportamento quadrático (Figura 4). Já para os níveis testados $(0,5$ e $1 \mu \mathrm{M})$, observou-se comportamento linear, o que está de acordo com PASQUAL et al. (1991), que encontraram uma maior indução da multiplicação de brotos de amoreira-preta com a adição de uma auxina sintética.

Para altura das brotações, observou-se que nas concentrações de 0 e $1 \mu \mathrm{M}$ de AIB, o aumento nos níveis de BAP resultou na diminuição do

Ciência Rural, v. 32, n. 5, 2002. 


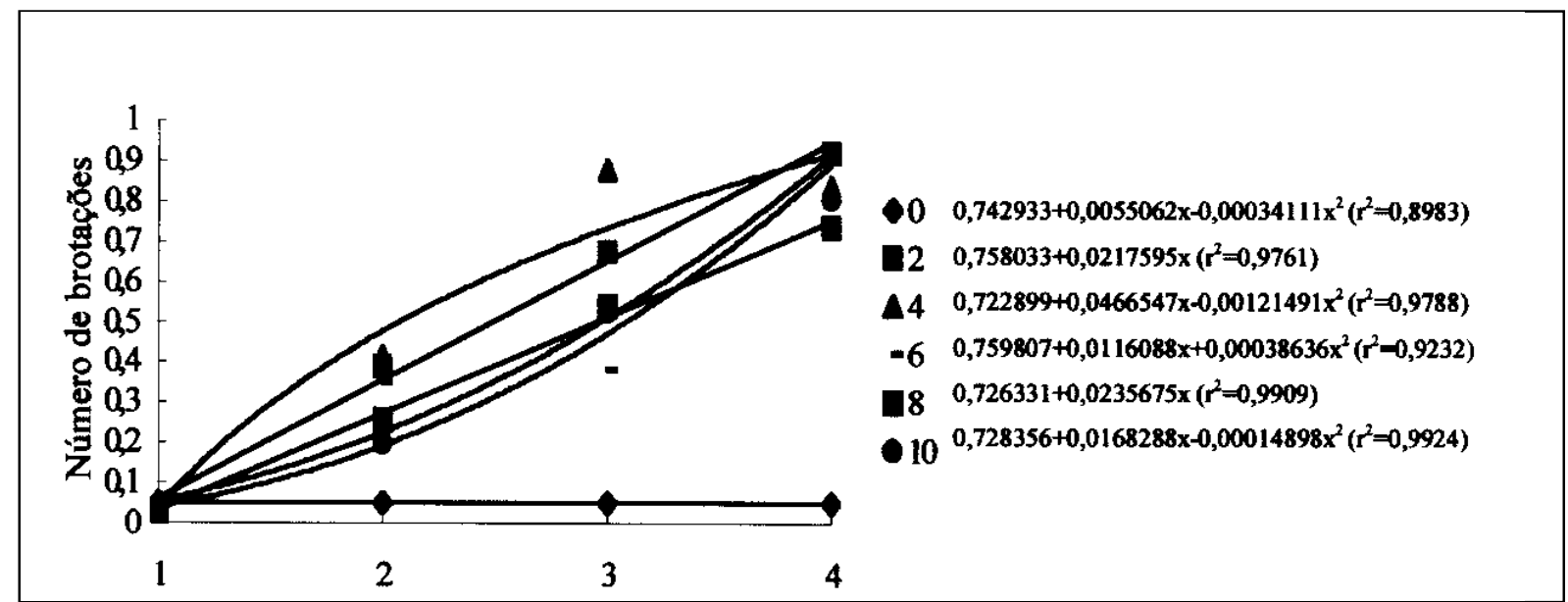

Figura 3 - Número de brotações de amoreira-preta cv. Tupy sob diferentes concentrações de BAP ( $\mu$ M), no período de 4 semanas. Pelotas, 2000.

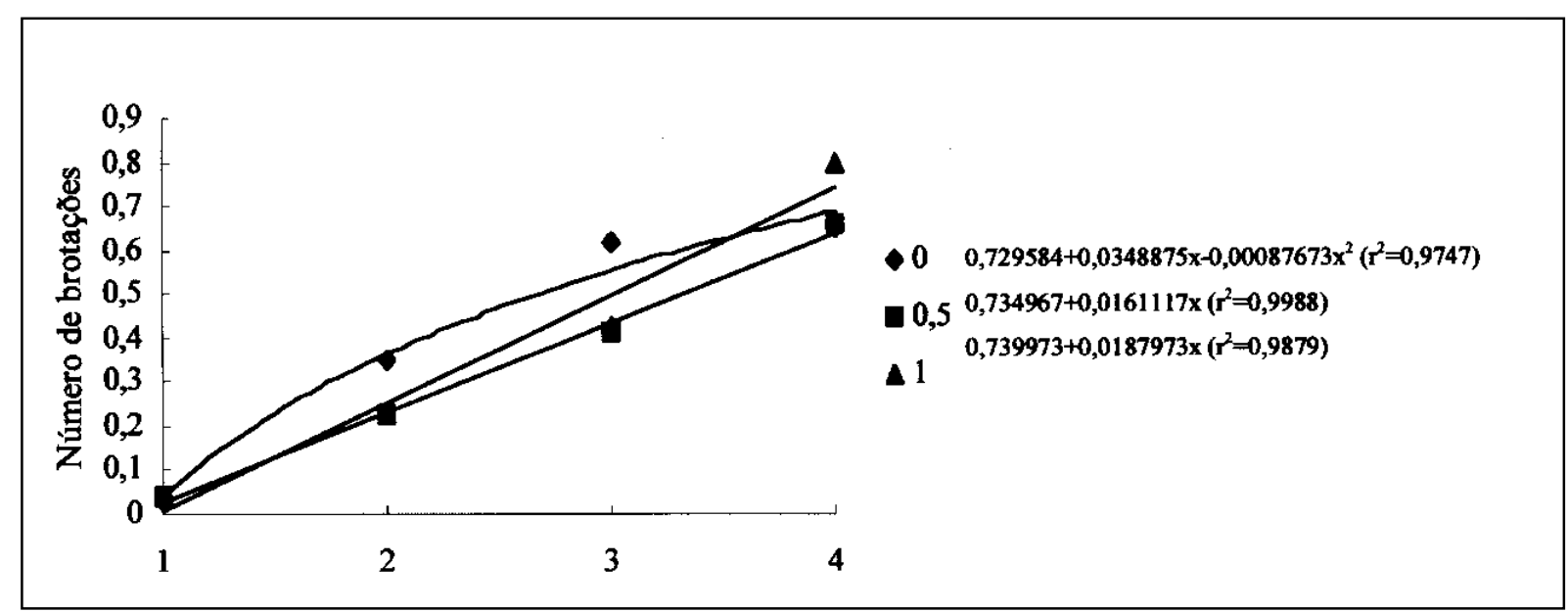

Figura 4 - Número de brotações de amoreira-preta cv. Tupy sob diferentes concentrações de AIB $(\mu \mathrm{M})$, no período de 4 semanas. Pelotas, 2000.

comprimento médio das brotações (Figura 5). A associação de $0,5 \mu \mathrm{M}$ de AIB com os níveis de BAP, apresentou comportamento quadrático, com redução no comprimento das brotações até o nível de $7 \mu \mathrm{M}$ de BAP. Verificou-se que, de modo geral, com o aumento dos níveis de BAP para todas as concentrações de AIB, houve redução na altura média das brotações, concordando com LANE (1979), LESHEM et al. (1988), que mencionam ser tóxico o uso de citocinina em níveis elevados, caracterizando-se principalmente, pelo demasiado enrosetamento e falta de alongamento das culturas.

Para a variável taxa de multiplicação (Figura 6), a concentração de $1 \mu \mathrm{M}$ de AIB associada com BAP influenciou negativamente, até a

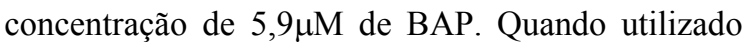
isoladamente, o BAP apresentou ponto de máxima eficiência no nível de $5,1 \mu \mathrm{M}$ (taxa de multiplicação igual a 3,23), o que está de acordo com MAYER et al. (1996) que, propagando as cultivares de amoreira-preta Tupy, Cherokee e Caiagangue, obtiveram boa multiplicação de brotos no meio contendo $4,4 \mu \mathrm{M}$ daquela citocinina. Para o nível de $0,5 \mu \mathrm{M}$ de $\mathrm{AIB}$, em todos os níveis de BAP, observou-se que não houve diferença significativa para a variável taxa de multiplicação.

\section{CONCLUSÃO}

Pelos resultados obtidos no experimento pode-se concluir que a utilização de 6benzilaminopurina promove aumento na taxa de multiplicação da amoreira-preta cv. Tupy até a concentração de $5,1 \mu \mathrm{M}$. 


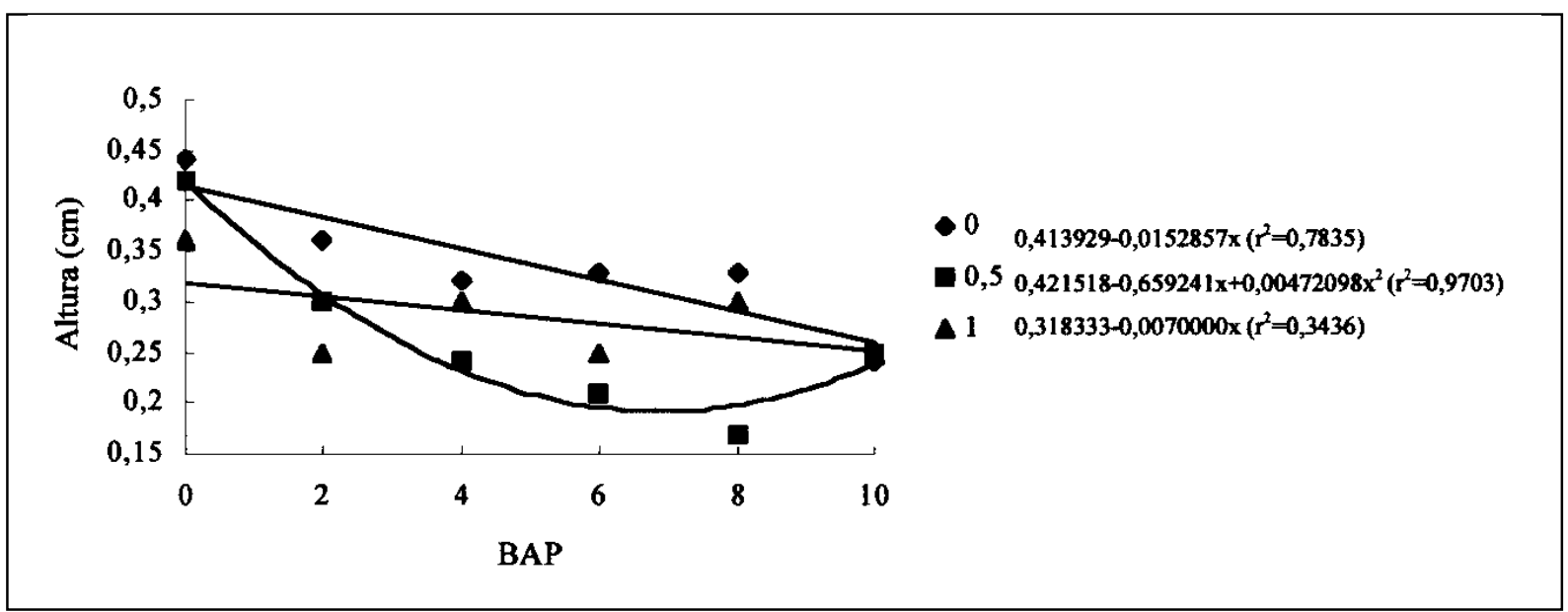

Figura 5 - Altura das brotações de amoreira-preta cv. Tupy sob diferentes concentrações de BAP e AIB ( $\mu$ M). Pelotas, 2000.

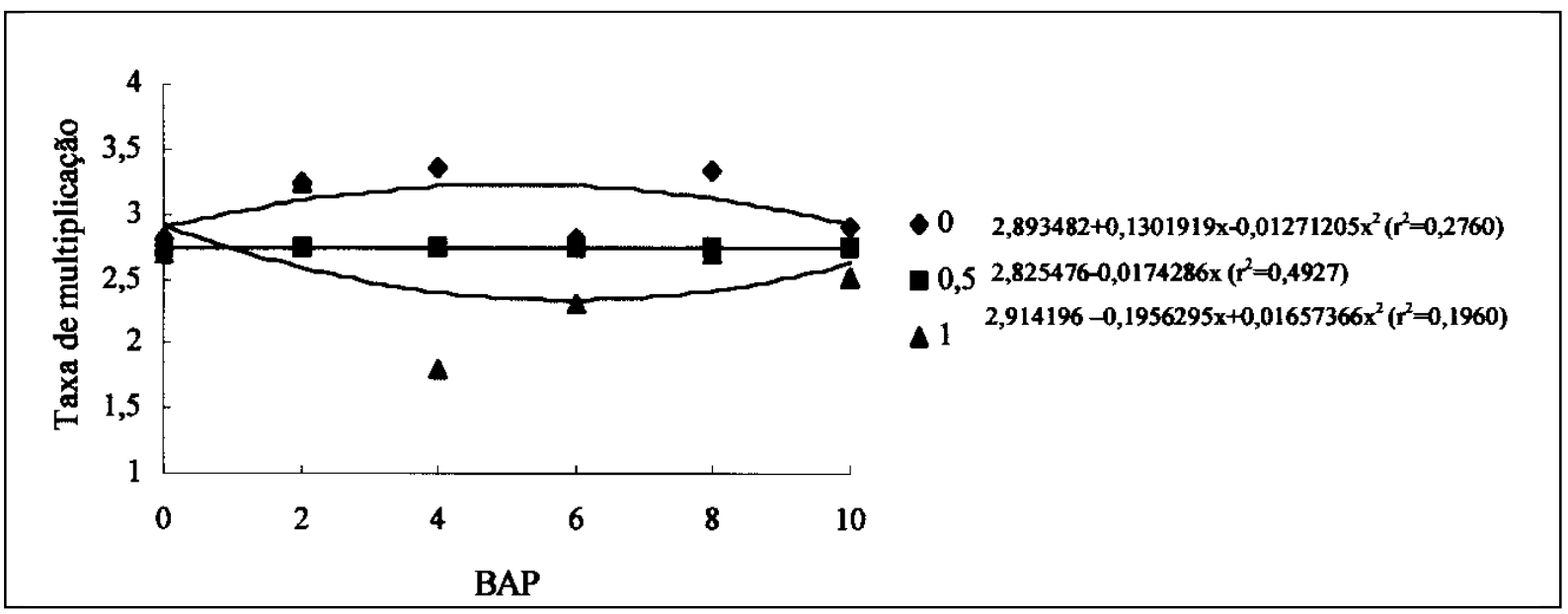

Figura 6 - Taxa de multiplicação de amoreira-preta cv. Tupy sob diferentes concentrações de BAP e AIB ( $\mu$ M). Pelotas, 2000.

A multiplicação in vitro da amoreira-preta cv. Tupy pode ser realizada sem a presença de ácido indolbutírico no meio de cultura.

\section{REFERÊNCIAS BIBLIOGRÁFICAS}

BASSOLS, M.C. A cultura da amora - preta. Pelotas - RS : Embrapa, 1980. 11p. (Circular Técnica n.4).

BASSOLS, M.C., MOORE, J.N. Perspectivas da amora - preta no Rio Grande do Sul. In: CONGRESSO BRASILEIRO DE FRUTICULTURA, 5, 1979, Pelotas. Anais... Pelotas : SBF, 1979. p.98-129.

BHOJWANI, S.S., MULLINS, K., COHEN, D. In vitro propagation of Pyrus pyrifolia. Scientia Horticulturae, Amsterdam, v.23, p.247-254, 1984.

BROOME, O.C., ZIMMERMAN, R.H. In vitro propagation of blackberry. HortScience, Alexandria, v.13, n.2, p.151-153, 1978.
DONNELLY, D.J., STACE-SMITH, R., MELLOR, F.C. In vitro culture of three Rubus species. Acta Horticulturae, Wageningen, n.112, p.69-75, 1980.

GEORGE, E.F. Plant propagation by tissue culture. Part II In Practice. Edingdon, Wilts : Exegetics, 1996. 1361p.

GEORGE, E.F., SHERRINGTON, P.D. Plant propagation by tissue culture. Eversley : Exegetics, 1984. 709p.

GRATTAPAGLIA, D., MACHADO, M.A. Micropropagação. In: TORRES, A.C., CALDAS, L.S. T écnicas e aplicações da cultura de tecidos de plantas. Brasília: ABCTP/Embrapa, 1990. p.99-169.

HU, C.Y., WANG, P.J. Meristem, shoot tip and bud culture. In: EVANS, D.A., SHARP, W.R., et al. Handbook of plant cell cultures. New York : Macmillan, 1983. V.1, p.177-227.

LANE, W.D. Regeneration of pear plants from shoot meristem-tips. Plant Science Letters, Limerick, v.16, p.337-342, 1979. 
LEE, H. J., KO, K. C. Effects of culture media and plant hormones on shoot tip culture of Fuji apple cultivar (Malus domestica). Seoul National University Journal of Agricultural Sciences, Seoul, v.9, n.1, p.67-77, 1984.

LESHEN, B., WERKER, E., SHALEV, D. P. The effect of cytokinins on vitrification in melon and carnation. Annals of Botany, London, v.62, p.271-276, 1988

LUNDERGAN, C. A., JANICK, J. Regulation of apple shoot proliferation and growth in vitro. Horticultural Research, Edinburgh, n.20, p.19-24, 1980.

MARINO, G. Moltiplicazione e radicazione in vitro del peso cv. "William". Revista di Frutticoltura e di Ortofloricoltura Italiana, Bologna, v.68, p.95-106, 1984.

MAYER, M. D. B., PASQUAL, M., OLIVEIRA, P. D. Propagação in vitro da amora-preta: Efeito de diferentes reguladores de crescimento e sulfato de adenina. In: CONGRESSO BRASILEIRO DE FRUTICULTURA, 14, 1996, Curitiba. Anais... Curitiba : Sociedade Brasileira de Fruticultura, 1996. p.56.

MURASHIGE, T., SKOOG, F. A revised medium for rapid growth and bioassays with tobacco tissue culture. Physiologia plantarum, Kobenhavn, v. 15, p.473-497, 1962.

NEZI, A. N., TREVISAN, R., PIUMA, M. T., et al. Efeito do TDZ e BAP na multiplicação in vitro da amora-preta (Rubus sp.) cv. Guarani. In: CONGRESSO BRASILEIRO DE
FRUTICUltURA, 15, 1998, Poços de Caldas. Anais... Poços de Caldas : Sociedade Brasileira de Fruticultura, 1998. p.90.

PASQUAL, M., PEIXOTO, P. H. P., SANTOS, J. C. dos., et al Propagação in vitro da amora-preta (Rubus sp) cv. Ébano: Uso de reguladores de crescimento. Ciência e Prática, Lavras, v.3, p.282-286, 1991.

RODRIGUES, D. Amora-preta rende R\$15 mil por hectare. Pelotas : Embrapa Clima Temperado,1999. N.2, p.4.

SKIRVIN, R. M., CHU, M. C., GOMEZ, E. In vitro propagation of thornless trailing blackberries. HortScience. Alexandria, v. 3, p.310-312, 1981.

SRISKANDARAJAH, S., MULLINS, M. G., NAIR, Y. Induction of adventitions rooting in vitro in difficult to propagate cultivars of apple. Plant Science Letters, Limerick, v.24, p.1-9, 1982

ZIMMERMAN, R.H. Micropropagation of fruit plants. Acta Horticulturae, Wageningen, n.120, p.217-222. 1981

ZONTA, E. P., MACHADO, A. A. SANEST - Sistema de análise estatística para microcomputadores. Pelotas: DMEC/IFM/UFPel, 1987. 138p. 